\title{
Laparoscopic inguinal hernia repair in children using the percutaneous internal ring suturing technique - own experience
}

\author{
Przemysław K. Wolak ${ }^{1,2}$, Dariusz Patkowski ${ }^{3}$ \\ ${ }^{1}$ Institute of Nursing and Obstetrics, Faculty of Health Sciences, Jan Kochanowski University, Kielce, Poland \\ ${ }^{2}$ Department of Pediatric Surgery, Urology and Traumatology, Wladyslaw Buszkowski Children's Hospital, Kielce, Poland \\ ${ }^{3}$ Department of Surgery and Pediatric Urology, University of Medicine, Wroclaw, Poland
}

Videosurgery Miniinv 2014; 9 (1): 53-58 DOI: $10.5114 /$ wiitm.2014.40389

\begin{abstract}
Introduction: Percutaneous internal ring suturing (PIRS) is a method of laparoscopic herniorrhaphy, i.e. percutaneous closure of the internal inguinal ring under the control of a telescope placed in the umbilicus.

Aim: To evaluate the usefulness of the PIRS technique.

Material and methods: Fifty-five children (39 girls and 16 boys) underwent surgery using this method in our institution between 2008 and 2010.

Results: In 10 cases the presence of an open inguinal canal on the opposite side was also noted during surgery, and umbilical hernia was recognized in 2 patients. In 5 cases it was necessary to convert to the open surgery because of the inability to continue the laparoscopic procedure. In 1 case, male pseudohermaphroditism was diagnosed during surgery. Recurrent inguinal hernia required a conventional method of surgery in 1 child. Other children did not exhibit the characteristics of hernia recurrence. The inguinal canals were followed up with postoperative ultrasound examination in 29 children. In 23 children, the ultrasound examination showed no dilatation of the inguinal canal. In the other 6 children dilatation of the inguinal canal or the presence of fluid within the inguinal canal was observed during ultrasound. In 6 children symptoms such as swelling and soreness around the inguinal canal developed within 3 to 6 months after surgery.

Conclusions: Inguinal hernia surgery using the PIRS procedure is an alternative, effective, minimally invasive method of surgery. Visualization of the peritoneal cavity allows for detection of other abnormalities, as well as for performing other procedures during the same session (such as closing the contralateral inguinal canal or umbilical hernia surgery).
\end{abstract}

Key words: laparoscopic surgical technique, inguinal hernia, laparoscopic hernia repair, children, percutaneous internal ring suturing.

\section{Introduction}

Congenital indirect inguinal hernia, occurring in about 1 to $5 \%$ of the pediatric population, is among the most common diseases in children that require operative treatment [1-3]. This type of inguinal hernia is diagnosed 8 to 10 times more often in boys than in girls, with $60 \%$ of cases occurring on the right side and $10 \%$ of cases being diagnosed as bilateral hernia. In premature newborns the risk of bilateral congenital oblique inguinal hernia increases to 44$55 \%[4,5]$. Pain and the risk of incarceration are the most important indications for operative treatment of inguinal hernia in children. In addition to conventional open techniques of inguinal hernia surgical repair, there have been many reports regarding the

\section{Address for correspondence}

Przemysław K. Wolak MD, PhD, Faculty of Health Sciences, Jan Kochanowski University, Al. IX Wieków Kielc 19, 25-317 Kielce, Poland,

phone: +48 501525 549, e-mail: przemyslaw.wolak@ujk.edu.pl 


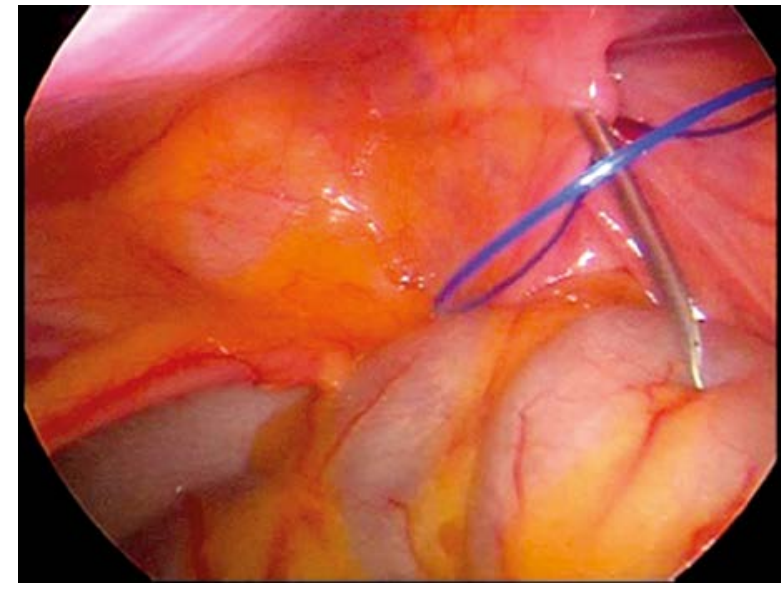

Photo 1. Laparoscopic view of inguinal region (during the PIRS procedure)

possibility of laparoscopic treatment of inguinal hernia since the 1990s [6-12]. In 2004, in Poland, Patkowski introduced a method of laparoscopic herniorrhaphy using his own technique. The procedure is called "percutaneous internal ring suturing" (PIRS). It involves the percutaneous closure of the internal inguinal ring under the control of a telescope placed in the umbilicus [13-15] (Photos 1 and 2).

\section{Aim}

To present our experience and results of the laparoscopic repair of congenital oblique inguinal hernia in children using the method introduced by Patkowski (PIRS).

\section{Material and methods}

Fifty-five children underwent laparoscopic repair of congenital oblique inguinal hernia using the PIRS technique between 2008 and 2010 (from 13.05.2008 until 23.09.2010) in the Department of Surgery, Urology and Traumatology of the Provincial Specialist Children's Hospital in Kielce. A surgeon trained in the PIRS technique performed the laparoscopic procedures in all patients. The only exceptions to the latter were the operations in the first 9 girls that were considered training procedures that were aided by the author of the PIRS technique. In the case of all children a conversation regarding the method of treatment with the parents took place, and the conventional method of open surgery was proposed as an alternative. However, the parents did not choose the conventional method of open

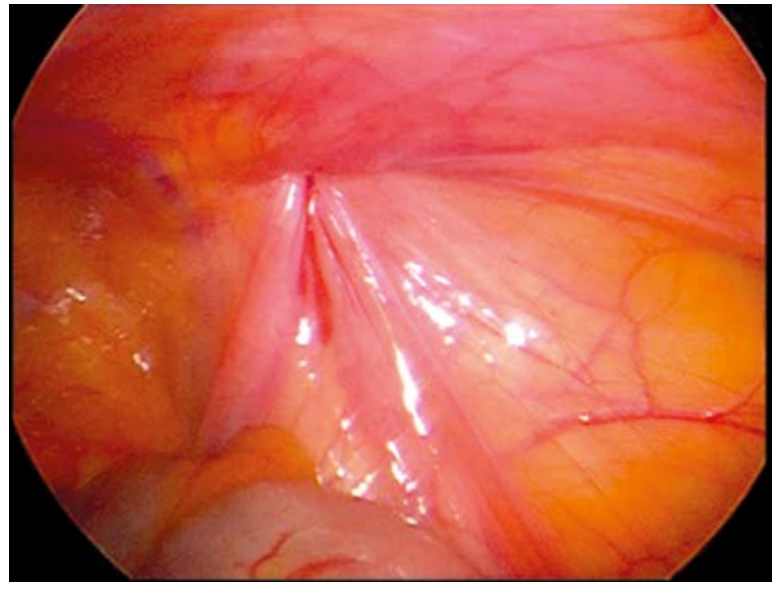

Photo 2. Laparoscopic view of inguinal region (after the PIRS procedure)

surgery in any case and agreed in writing to the laparoscopic procedure, with only the possibility of conversion to the open technique. Only in one case of recurrent hernia after laparoscopic hernia repair did the parents not consent again to the operation using re-PIRS. The telescope was used to control all procedures, with optics of $3.5 \mathrm{~mm}$ or $5 \mathrm{~mm}$, and an angle of view of $30^{\circ}$. The whole procedures were recorded in electronic media. The insufflation pressure in the peritoneal cavity was maintained at $8 \mathrm{~mm}$ to $10 \mathrm{~mm} \mathrm{Hg}$. The internal opening of the inguinal canal was closed using non-absorbable 2-0 monofilament sutures. The wound in the umbilicus was closed in layers using absorbable 3-0 sutures, and the skin was closed with non-absorbable 4-0 or 5-0 monofilament sutures. The patients were discharged on the first postoperative day. All children reported to the outpatient clinic for a follow-up visit on the $7^{\text {th }}$ day after the laparoscopic surgery. At the time of the second follow-up visit (at least 3 months after surgery) parents of all children were given a questionnaire which asked whether after the surgery there were any alarming symptoms (such as recurrent hernia, swelling or lump in the groin, local pain, etc.), how quickly the child had resumed physical activity, how the scar tissue in the navel would have been rated, whether there had been any palpable stitches in the groin area, and whether they would choose that method of treatment again, or would recommended it to other parents. In some patients, ultrasound was performed both in supine and standing positions (examinations were performed at the UItrasound Laboratory of the Department of Radiology 
Provincial Children's Specialist Hospital in Kielce) The ultrasound examination was performed in all children in whom a swelling or lump in the inguinal region was observed, with suspicion of recurrent hernia, or in all cases when the parents asked for the test, even in the absence of any symptoms.

\section{Results}

A total of 67 PIRS laparoscopic procedures were performed. In 55 children (39 girls and 16 boys) who underwent surgery, a right-sided inguinal hernia was diagnosed before the operation in 32 , left-sided in 15, and bilateral in 8 cases. Additionally in 10 children an open inguinal canal on the opposite side was found during laparoscopic surgery (clinically hidden inguinal hernia, not recognized before surgery) - in 6 cases on the right side and in 4 cases on the left side. Taking into consideration the possible difficulties arising from the use of this technique in boys (the lack of experience may result in spermatic cord damage by clamping it in the tied knot) the first 9 procedures were performed in girls, and only after mastering the operative technique did we then continue operating on patients regardless of gender. Patients ranged in age from 6 weeks to 16 years (average age 5.33 years). A $3.5 \mathrm{~mm}$ telescope was used during procedures in 9 children and $5 \mathrm{~mm}$ was used in all remaining cases (all hernia repairs were performed with an angle of view of $30^{\circ}$ ). In 10 patients with preoperatively diagnosed unilateral hernia an open inguinal canal on the opposite side was found during laparoscopic surgery (in 6 cases on the right side, and the other 4 on the left side), which was treated using the same technique. The mean anesthesia time for laparoscopic surgery was $46 \mathrm{~min}$ and $32 \mathrm{~s}$ (minimum $30 \mathrm{~min}$, maximum $75 \mathrm{~min}$ ) - the time taken from the entrance of the patient to the operating room, through intubation, laparoscopic surgery, until waking up the patient (i.e. the total time spent in the operating room). The mean operative time was 29 min $3 \mathrm{~s}$ (min: $15 \mathrm{~min}, \max : 65 \mathrm{~min}$ ) - the time taken from the beginning of cleaning the operative field to dressing the umbilicus. In the case of bilateral hernia the mean operative time was 31 min $6 \mathrm{~s}$ (min: 17 min, max: $40 \mathrm{~min}$ ), and the mean for the one-sided procedure was $28 \min 2 \mathrm{~s}$ (min: $15 \mathrm{~min}$, max: 45 min). In 5 cases, after the intraoperative assessment of internal openings of inguinal canals, the laparoscopic procedure was converted to the con- ventional open surgery. In 1 child there was no open deep inguinal ring - conversion because of direct inguinal hernia. In 1 child an ovary accreted to the internal opening was found (inability to discharge the ovary into the abdominal cavity). In 1 child spermatic cord hydrocele was found (uncertainty of the effectiveness of the method after puncture and draining of hydrocele). A similar situation occurred in 1 girl with a large hydrops of Nuck's canal. In 1 child with bilateral hernia and feminine phenotype, intraoperatively gonads were found, which macroscopically resembled nuclei more than ovaries. The samples were taken and the small pelvis was meticulously inspected (no uterus or oviducts were found). Vaginoscopy revealed a short vagina without a cervix, and cystoscopy showed normal openings of both ureters. In this case, wide internal openings of inguinal canals were not closed. Based on further studies testicular feminization syndrome was diagnosed. In 2 children iliac vessels were punctured during needle manipulation (Photo 3). The hematoma was stopped with external compression to the upper branch of the pubic bone. Laparoscopic surgery was completed only in the absence of further bleeding and growth of retroperitoneal hematoma.

All patients operated on with that technique were followed up at least once, at least 3 months after surgery. Fifty questionnaires were given to the parents and all of them were returned completed (the questionnaires were given only to the parents of children in whom the PIRS procedure was performed and there was no need for a conversion procedure). In that analysis, in 42 children there were no

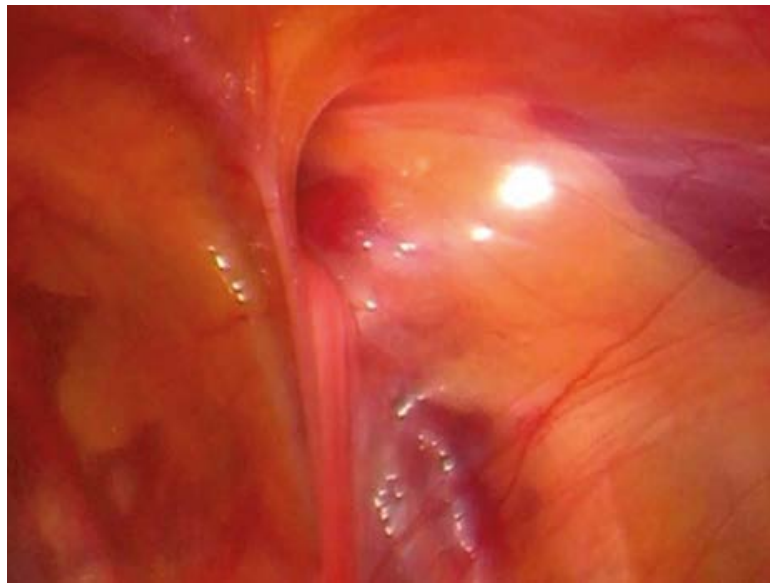

Photo 3. Laparoscopic view of inguinal region (PIRS procedure - accidental puncture of iliac vessels during needle manipulation) 


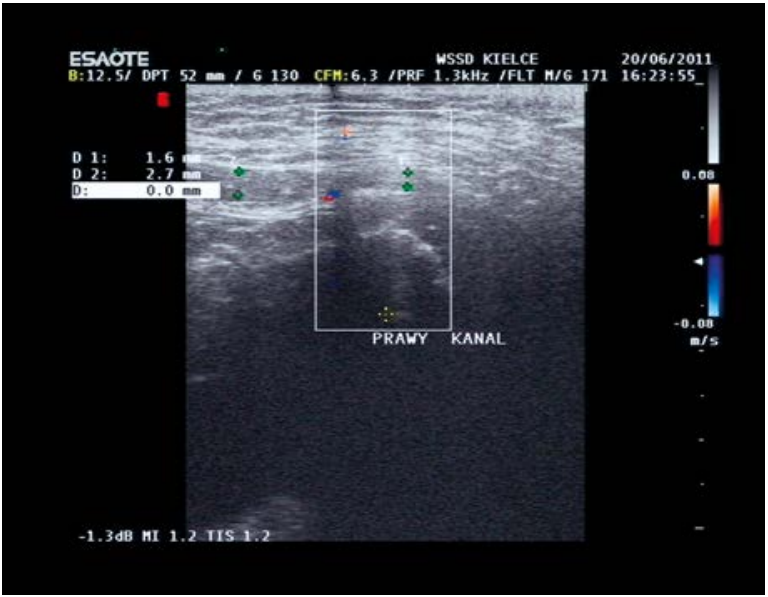

Photo 4. Inguinal canal during ultrasound examination (after the PIRS procedure)

alarming signs or symptoms after surgery. Parents of 6 patients observed after surgery possible temporary symptoms of hernia recurrence, which finally resolved up to 6 months after surgery (swelling of the tissues around the upper pole of the groin). In 2 cases groin pain was reported by the parents and recurrent hernia in 1 case. All children returned to physical activity on day 1 after treatment. The scar in the navel was very little visible or almost invisible and none of the parents raised esthetic objections. In 6 children the parents could palpate the subcutaneous suture on a deep ring of the inguinal canal. When asked whether they would recommend this method to other parents, 48 people answered "yes, definitely", one person answered "probably yes" (the child had swelling around the inguinal canal up to 3 months after surgery), and one person said that they would not recommend this method to other parents (the child had a right-sided inguinal hernia recurrence after the initial bilateral PIRS procedure). The parents did not consent to laparoscopic re-surgery, so 3 months after the laparoscopic procedure open conventional surgery was performed. In 29 patients the inguinal canals were followed up with ultrasound examination. In 23 children, the test showed a non-dilated inguinal canal. In the remaining 6 children, in 4 cases $2-3 \mathrm{~mm}$ widening of the inguinal canal was found, and in 2 cases the presence of fluid space $(18 \mathrm{~mm} \times 5 \mathrm{~mm} \times 8 \mathrm{~mm}$ and $16 \mathrm{~mm} \times 6 \mathrm{~mm} \times$ $6 \mathrm{~mm}$ ) without evidence of hernia recurrence during ultrasound was noted. In 6 children recurrent hernias were suspected, of whom in 4 children the swelling disappeared during the 3 to 6 months follow-up period, and there was no dilatation of inguinal canals during ultrasound examination (Photo 4). In the remaining 2 children, a small hydrops of Nuck's canal was found in one and a localized intraperitoneal fluid collection (without communication to the inguinal canal) in the other (Table I).

The cosmetic result was very good in all cases. The scar in the navel was almost invisible after a short period of time. The place of skin puncture above the inguinal canal was not visible in all cases. In lean children only a thickening corresponding to the subcutaneous suture could be palpated (in 11 children). There was no infection in the surgical wound in any case.

\section{Discussion}

Congenital inguinal hernia surgery in children using the conventional open method has been performed for a long time. The first mentions of this type of surgery are derived from Celsus (25 AD) and Galen, who described the presence of vaginal outpouching of the peritoneum (176 AD) [1, 15]. The relatively small number of surgical techniques that have been used to date could be considered as an indirect proof of their effectiveness, with the basis of treatment being closure of the sac of the hernia at the level of the deep inguinal ring [15]. Misra was the first to repair an inguinal hernia in a child, clos-

Table I. Ultrasound examination after PIRS procedure

\begin{tabular}{|c|c|c|c|c|}
\hline \multirow{4}{*}{$\begin{array}{l}\text { Number of } \\
\text { patients } \\
\text { undergoing } \\
\text { ultrasound } \\
\text { examination after } \\
\text { PIRS procedure }\end{array}$} & \multicolumn{2}{|c|}{$\begin{array}{l}\text { Inguinal canals not distended during } \\
\text { ultrasound examination }\end{array}$} & \multicolumn{2}{|c|}{$\begin{array}{l}\text { Presence of visible distension of inguinal canals } \\
\text { or localized fluid during ultrasound examination }\end{array}$} \\
\hline & $\begin{array}{l}\text { No signs or symptoms } \\
\text { of inguinal hernia } \\
\text { recurrence }\end{array}$ & $\begin{array}{l}\text { Suspicion of presence } \\
\text { of signs and/or } \\
\text { symptoms of inguinal } \\
\text { hernia recurrence }\end{array}$ & $\begin{array}{l}\text { No signs or symptoms } \\
\text { of inguinal hernia } \\
\text { recurrence }\end{array}$ & $\begin{array}{l}\text { Suspicion of presence } \\
\text { of signs and/or } \\
\text { symptoms of inguinal } \\
\text { hernia recurrence }\end{array}$ \\
\hline & 19 (66\%) & $4(14 \%)$ & $4(14 \%)$ & $2(7 \%)$ \\
\hline & \multicolumn{2}{|c|}{$23(79 \%)$} & \multicolumn{2}{|c|}{$6(21 \%)$} \\
\hline
\end{tabular}


ing the deep inguinal ring during a laparoscopic procedure [6]. It was a big step toward the application of laparoscopic surgery in the treatment of inguinal hernia in children. El-Gohary was in 1997 among the first to report that type of hernia repair in children [7]. The surgery was performed only in girls, and involved establishment of a self-locking loop placed on the hernia sac. Then, Schier locked a deep inguinal ring using z-plasty [8]. These procedures require placement of 3 ports (optics and 2 working tools) into the peritoneal cavity [9]. Patkowski developed his own laparoscopic technique of inguinal hernia repair in children. The advantage of this technique is the use of only one optical port, and the lack of manipulation and suturing with instruments inside the peritoneal cavity. Laparoscopic single port surgery in a child was also used by Bryks-Laszkowska et al. in nephrectomy [16]. After assisting Patkowski in Wroclaw and then after performing a few laparoscopic procedures under his supervision in Kielce, we started using this method of inguinal hernia repair on our own. Initially only girls were qualified for the procedure, because of the risk of vas deferens injury, which is confirmed by others as well [7-9, 1720]. The only identified intraoperative complication was the puncture of the iliac vessels during needle manipulation in 2 children. In one of these patients a slight swelling persisting after surgery and palpable resistance above the inguinal canal suggested an early recurrence of hernia. These symptoms resolved completely by the time of follow-up ultrasound 3 months after the initial procedure. Given that inflammation was limited to the appendix (acute serous appendicitis) the PIRS procedure was performed after obtaining parental consent. After surgery in these patients no inflammation or encapsulated infected fluid collections in the inguinal canals were found. All cases of conversion to open surgery were caused by the anatomical situation. We realized that those patients could be operated on using the PIRS technique, but it would extend the operation time, and thus increased the risk of hernia recurrence. There were no postoperative complications after conversion to open surgery. In one case, the procedure was not continued because of suspected intersex and only diagnostic laparoscopy with biopsy of the gonads was performed. In our opinion, closure of open inguinal canals in that child was not advisable due to the possibility of further treatment of sex differentiation disorders. We repaired the existing um- bilical hernia (in 4 children, including 2 children with clinically hidden hernia). The children were able to walk on day 1 after surgery. Surveys conducted among the parents of our patients showed postoperative acceptance of the method. In 6 patients transient symptoms of hernia recurrence were observed after surgery, which definitely resolved by 6 months after the operative procedure. Follow-up ultrasound examination in these patients showed no distension of inguinal canals. Ścierski and Roethe described the role of ultrasonographic diagnosis of the presence of inguinal hernia [21]. Therefore, we believe that placement of internal sutures on the internal inguinal canal opening can lead to natural tapering of the inguinal canal and no recurrence of hernia, as seen in the case of umbilical hernia in neonates and infants. That would be in line with the report of spontaneous regression of the open peritoneal vaginal outpouching in premature infants in $67 \%$ to $91 \%$ of cases [22]. These chances are even greater for prematurely born girls, if the contents are intestinal loops [23]. This is consistent as well with observations of Patkowski of 1 patient in whom wide open inguinal canals regressed spontaneously after several laparoscopic procedures performed for other reasons [15]. The cosmetic effect of laparoscopic surgery was very good. Subcutaneous sutures could only rarely be palpated and in very lean patients for a while after surgery there was a slight bulge visible on the skin. The umbilical scar was almost invisible.

\section{Conclusions}

Inguinal hernia repair using the PIRS technique allows for visualization of the peritoneal cavity, and thus the ability to detect other abnormalities (in our case intersex), repair a contralateral open inguinal ring that would be a potential hidden hernia, or repair an umbilical hernia (the navel is used for the introduction of the optical trocar). The duration of bilateral hernia surgery is only slightly longer than the one-sided one when using the PIRS technique (in the case of conventional open surgery this time is twice as long, as it consists of two separate procedures with virtually no common parts beyond cleaning the surgical field). The PIRS technique allows for a quick return to full fitness of children. It does not leave visible scars, and the complication rate is not significantly higher than after conventional methods of surgery, which is offset by the possibility of 
performing additional relevant procedures. Inguinal canal ultrasound can provide valuable assistance in case of suspected recurrence after inguinal hernia surgery by PIRS. The vast majority of parents are satisfied with the application of this method in their children and would recommend it to others.

\section{References}

1. Czernik J. Przepuklina pachwinowa i pępkowa [Polish]. In: Chirurgia dziecięca. Czernik J, et al. Wydawnictwo Lekarskie PZWL, Warsaw 2005; 649-62.

2. Weiner ES, Touloukian RJ, Rogers BM, et al. Hernia survey of the section on surgery of the American Academy of Pediatrics. J Pediatr Surg 1996; 31: 1166-9.

3. Kapur P, Caty MG, Glick PL Paediatric hernias and hydroceles. Pediatr Clin North Am 1998; 45: 773-89.

4. Rowe MI, Copelson, LW, Clatworthy HW The patent processus vaginalis and the inguinal hernia. J Pediatr Surg 1969; 4: 102.

5. Boolock GR, Todd PJ. Inguinal hernia are common in preterm infants. Arch Dis Child 1985; 60: 669-70.

6. Misra D, Hewitt G, Potts SR, et al. Transperitoneal closure of the internal ring in incarcerated infantile inguinal hernias. J Pediatr Surg 1995; 30: 95-6.

7. El-Gohary MA. Laparoscopic ligation of inguinal hernia in girls. Ped Endosurg Innov Tech 1997; 1: 185-8.

8. Schier F. Laparoscopic herniorrhaphy in girls. J Pediatr Surg 1998; 33: 1495-7.

9. Montupet P, Esposito C, Roblot-Maigret B. Laparoscopic treatment of congenital inguinal hernia in children. J Pediatr Surg 1999; 34: 420-3.

10. Michalik M, Frask A, Klawiter A. Inguinal hernia laparoscopic repair [Polish]. Videosurgery Miniinv 2007; 2: 150-5.

11. Śmietański M, Kitowski J, Tarasiuk D. Laparoscopic abdominal hernia repair with SILS ${ }^{\circledR}$ port - our first experiences. Videosurgery Miniinv 2009; 4: 76-8.

12. Pesta W, Kurpiewski W, Łuba $M$, et al. Single incision laparoscopic surgery transabdominal pre-peritoneal hernia repair case report. Videosurgery Miniinv 2012; 7: 137-9.

13. Patkowski D, Czernik J, Chrzan R. The effi cacy of Percutaneous Internal Ring Suturing (PIRS) - a simple minimal invasive technique for inguinal hernia repair in children. J Lap Adv Surg Tech 2006; 16: 513-7.

14. Patkowski D, Chrzan R, Jaworski W, et al. Percutaneous internal ring suturing for inguinal hernia repair in children under three months of age. Adv Clin Exp Med 2006; 15: 851-6.

15. Patkowski D. Przezskórne zamknięcie pierścienia pachwinowego wewnętrznego w leczeniu przepukliny pachwinowej u dzieci - opis i ocena wartości klinicznej metody własnej [Polish]. Rozprawa na stopień doktora habilitowanego. Akademia Medyczna we Wrocławiu, Wrocław 2007.

16. Bryks-Laszkowska A, Gołębiewski A, Czauderna P. Laparoscopic single port surgery nephrectomy in a child - initial experience. Videosurgery Miniinv 2012; 7: 304-6.

17. Becmeur F, Philippe P, Lemandat-Schultz A, et al. A continuous series of 96 laparoscopic inguinal hernia repairs in children by a new technique. Surg Endosc 2004; 18: 1738-41.
18. Endo M, Ukiyama E. Laparoscopic closure of patent processus vaginalis in girl with inguinal hernia using specially devised suture needle. Pediatr Endosurg Innov Tech 2001; 5: 187-91.

19. Lee $Y$, Liang J. Experience with 450 cases of micro-laparoscopic herniotomy in infants and children. Pediatr Endosurg Innov Tech 2002; 6: 25-8.

20. Prasad R, Lovvorn III HN, Wadie GM, et al. Early experience with needleoscopic inguinal herniorrhaphy in children. J Pediatr Surg 2003; 38: 1055-8.

21. Ścierski A, Roechte F. The significance of the use of ultrasound in diagnosing inguinal hernia [Polish]. Videosurgery Miniinv 2007; 2: 58-65.

22. Toki A, Watanabe Y, Sasaki K, et al. Adopt a wait-and-see attitude for patent processus vaginalis in neonates. J Pediatr Surg 2003; 38: 1271-3.

23. Oudesluys-Murphy AM, Teng HT, Boxma H. Spontaneous regression of clinical inguinal hernias in preterm female infants. J Pediatr Surg 2000; 35: 1220-1.

Received: 20.04.2013, accepted: 5.08.2013. 